\section{Gêneros jornalísticos na escola}

Journalistic genres in the school

Robson DEON (UTFPR) robson_deon@hotmail.com Márcia Andrea dos SANTOS (UTFPR) andreama25@gmail.com

\section{DEON, Robson; SANTOS, Márcia} Andrea dos. Gêneros jornalísticos na escola. Entrepalavras, Fortaleza, v. 6, n. 2, p. 322-334, jul./dez. 2016.

Resumo: Este trabalho objetiva discutir e expor uma experiência realizada através do PIBID de Linguística foi pautada sobre um projeto de estudo, compreensão e produção de textos do gênero jornalístico na escola. Os teóricos usados neste artigo, que fundamentaram a teoria e a prática do projeto na escola, são principalmente Bakhtin (2011), com sua concepção de linguagem e postulações sobre gêneros, Geraldi (1990; 2012), adotado aqui principalmente pela sua metodologia, que se subdivide em três etapas: a) Leitura e interpretação; b) Produção textual contextualizada; c) Análise Linguística. Como resultado, os alunos interpretaram, apreenderam e produziram novas modalidades de texto de modo eficaz.

Palavras-chave: Textos Jornalísticos. Gêneros discursivos. Concepção interacionista. 
Abstract: This work aims discuss and expose an experience realized through of PIBID of Linguistic, and which was guided on a project of study, comprehension and production of text of journalistic genres in the school. The theoretical referenced in this article, and which support the theory and practice of project, are principally Bakhtin (2011), with his language conception and postulations about genres, and Geraldi (1990; 2012), assumed here principally by his methodology, which subdivide in three parts: a) Reading and interpretation; b) Contextualized textual production; c) Linguistic analyses. As result, the students interpreted, learned, and produced new modalities of text effectively.

Keywords: Journalistic texts. Speech genres. Interactionist conception.

\section{Introdução}

Normalmente, no Ensino de Língua Portuguesa no colégio, os alunos não dispõem de textos atuais que circulam na sociedade. A maior parte dos textos estudados estão "pregados" e estagnados no livro didático, que é o suporte de diversos gêneros, mas que não são acessados autenticamente pelo aluno: uma notícia num livro didático, por exemplo, não é o mesmo que uma notícia em um jornal do dia.

Desse modo, os textos que constam no livro didático já são um contato virtual e simulado com língua, pois eles estão indiferentes à sociedade atual nas suas múltiplas e ininterruptas manifestações. Ainda, voltando ao exemplo da notícia no livro, ela não terá nenhuma importância no tocante à sua real função na sociedade, que é a de transmitir uma informação relevante ao momento. No máximo, se poderá entender a estrutura linguística interna e composicional recorrente do gênero notícia, o que tem muito mais a ver com a estrutura intrínseca da língua do que com a língua na sua relação interativa com a vida, o social e a cultura.

Em suma, o problema desses textos nos livros didáticos é o de serem estáticos, situados em outros contextos que não o dos alunos e da sociedade atual em que vivem. Ou seja, os textos impressos nos livros didáticos quase sempre "vivem" num mundo à parte, isolados do contexto social/atual do estudante. Na maioria das vezes, são textos ficcionais, os quais não suprem plenamente, ou de modo eficaz, a questão orientadora de que a língua deve estar em relação estreita com a vida social, como orientam os documentos educacionais e teóricos como Bakhtin (2011).

Trabalhando o professor desse modo, ou seja, sem elencar, selecionar e trazer à sala de aula textos atuais e "do momento", o aluno pode vir a aprender a língua de uma maneira artificial e se repetir o que 
v. 6 (2)

322-334

$\mathrm{jul} / \mathrm{dez}$

2016

acontecia no passado, quando os estudos eram centrados nas estruturas sistêmicas da língua e não no texto.

Ainda, agindo desse modo, o educando está sendo idealizado, pois ele não é considerado em toda sua dimensão. O aluno não é um ser ideal, além de estudante, é um ser social, concreto, real, situado no meio de uma comunidade específica, com cultura, costume e particularidades também específicas. Por isso, o ensino de língua portuguesa deve pontuar, através dos textos, essas questões relativas à vida, ao lugar, à condição econômica e social dos estudantes que fazem parte de uma comunidade escolar.

Entretanto, trazer textos atuais à sala de aula também exigiria do professor mais tempo para a coleta e a pesquisa. Por isso ele prefere usar textos já disponibilizados nos livros, o que facilita e agiliza a sua atividade. Porém, essa conduta do professor repetida ad infinitum prejudica o aprendizado pleno, pois não capacita e nem ativa os alunos para textos correntes na sociedade, e, assim, impossibilita-os a desenvolverem a competência discursiva relacionada com tais gêneros, bem como reduz as possibilidades de o aluno adquirir informação e conhecimento da sociedade atual em termos políticos, econômicos, culturais, sociais etc., conhecimentos que tais tipos de textos podem fornecer com mais propriedade.

Por exemplo, o gênero reportagem pode servir de modo efetivo para se conhecer um assunto com mais propriedade, e não apenas superficialmente. Uma reportagem sobre a seca no Nordeste pode ativar e aprimorar o conhecimento de um tema importante na sociedade brasileira que, talvez, o aluno saiba superficialmente. Uma reportagem sobre a violência ou criminalidade em determinada região do Brasil, por exemplo, pode despertar a consciência do aluno para um tema importantíssimo que ocorre na nossa sociedade. Os PCN orientam que o ensino deve conduzir o educando a um exercício de autonomia intelectual e pensamento crítico. Mas, para tal, é imprescindível o acesso a informações referentes aos assuntos principais da sociedade, assuntos que certos gêneros mais próximos do aluno, como o exemplo do gênero reportagem, podem fornecer. Nesse caso, a partir do acesso a dados, informações, temas, etc. o aluno pode construir o seu pensamento crítico mediado pela ação docente.

É precisamente para suprir essa necessidade observada em sala, a saber, a falta de textos relacionados com a vida do estudante e com a sociedade atual na qual ele vive, e, para com isso, "aumentar a 
consciência linguística do aluno" (BRASIL, 1998, p. 22), que o projeto do PIBID de linguística foi desenvolvido e orientado. A escola tem o importante papel de possibilitar ao aluno letramentos heterogêneos e múltiplos que o faça alargar seu conhecimento cultural, e é nesse sentido que o projeto do PIBID auxiliou-a.

Em acréscimo, e a favor do desenvolvimento em forma de projeto na escola, estão os próprios PCN, que afirmam que o desenvolvimento de

...projetos são excelentes situações para que os alunos produzam textos de forma contextualizada. [...] Podem [...] resultar em diferentes produtos: uma coletânea de textos de um mesmo gênero (poemas, contos de assombração ou de fadas, lendas, etc.), um livro sobre um tema pesquisado, uma revista sobre vários temas estudados, um mural, uma cartilha sobre cuidados com a saúde, um jornal mensal, um folheto informativo, um panfleto, os cartazes de divulgação de uma festa na escola ou um único cartaz. (BRASIL..., 1997, p.50)

Ainda, no mesmo documento (PCN, 1997, p.51), afirma-se que

...os projetos favorecem o necessário compromisso do aluno com sua própria aprendizagem. O fato de o objetivo ser compartilhado, desde o início, e de haver um produto final em torno do qual o trabalho de todos se organiza, contribui muito mais para o engajamento do aluno nas tarefas como um todo, do que quando essas são definidas pelo professor; determinadas práticas habituais que não fazem qualquer sentido quando trabalhadas de forma descontextualizada podem ganhar significado no interior dos projetos: a cópia, o ditado, a produção coletiva de textos, a correção exaustiva do produto final, a exigência de uma ortografia impecável, etc.

Portanto, a intenção do projeto não é contrariar, mas agregar e somar valor ao ensino de Língua Portuguesa (LP), possibilitando uma maior interatividade e proximidade dos estudantes com a língua que se fabrica em forma de textos dia após dia na sociedade. Segundo as Orientações Curriculares para o Ensino Médio (OCEM, 2006), a proposta de letramento está vinculada a de cidadania, de modo que o educando, além da formação e aprendizado da língua, se desenvolve como um cidadão. Para isso, a língua em sala de aula deve ser tratada como um fato social. Para ser tratada dessa forma, é necessário deixar para trás a língua essencialmente sistêmica e abstrata e vinculá-la à sociedade. Isso se faz mostrando os diversos usos da língua, em várias esferas da sociedade, ou seja, apresentando aos educandos os diversos gêneros do discurso que estão circulando socialmente.

Como benefício, o ganho no aprendizado fica evidente: 
v. 6 (2)

$322-334$

$\mathrm{jul} / \mathrm{dez}$

2016

apreensão dos novos usos da língua, e sua dinamicidade, objetividade e funcionalidade através dos gêneros jornalísticos. Talvez, se o projeto não viesse a ocorrer, os alunos não desenvolveriam a competência discursiva ${ }^{1}$ ligada a esses gêneros, uma vez que eles, como observado em sala de aula, são pouco ou escassamente trabalhados nos conteúdos do livro didático ou mesmo pelo professor.

Uma vez sabendo que os textos que mais refletem essa ideia (textos atuais) são, sem dúvida, os gêneros de texto pertencentes à esfera jornalística, logo eles serão as unidades ${ }^{2}$ que serão elencadas para serem trabalhados em sala. Essa categoria de textos é produzida diariamente, circula através de diversas mídias, e aborda temas e questões "da hora", e por isso são textos caracterizados pelos ares do momento, e que estão efetiva e ostensivamente próximos no espaço e no tempo em que os estudantes estão inseridos.

Portanto, o objetivo central do projeto foi aproximar os alunos desses gêneros de textos, e através deles conscientizá-los de que a língua é dinâmica, produtiva, relacionada estrita e estreitamente com a vida. Os textos de jornal, por exemplo, são os que estão mais próximos no tempo, os mais incorporados e sensíveis à sociedade, e que a refletem dia após dia, quase que initerruptamente. Fazer os alunos perceberem essa realidade concreta de linguagem se desdobrando dia após dia foi um dos objetivos centrais da proposta deste projeto do PIBID de Linguística.

\section{Aspectos teóricos e metodológicos da prática}

A definição teórica geral que orientou o projeto foi a concepção interacionista da linguagem. Dessa perspectiva, a linguagem é uma atividade dentre as tantas outras que o ser humano realiza, como correr, brincar, jogar, etc. O fato é que há várias modalidades de uso da linguagem nas quais a língua assume determinadas particularidades e especificidades. Então, nessa concepção, a língua é dinâmica e variada e

1 Competência discursiva, neste documento, está sendo compreendida como a capacidade se produzir discursos - orais ou escritos - adequados às situações enunciativas em questão, considerando todos os aspectos e decisões envolvidos nesse processo. (BRASIL, 1997, p.29)

2 Nessa perspectiva, não é possível tomar como unidades básicas do processo de ensino as que decorrem de uma análise de estratos, letras/fonemas, sílabas, palavras, sintagmas, frases, que, descontextualizados, são normalmente tomados como exemplos de estudo gramatical e pouco têm a ver com a competência discursiva. Dentro desse marco, a unidade básica do ensino só pode ser o texto. (BRASIL, 1998, p.23) 
"é por meio dela que o homem se comunica, tem acesso à informação, expressa e defende pontos de vista, partilha ou constrói visões de mundo, produz conhecimento." (BRASIL..., 1997, p.15).

O trabalho com textos jornalísticos, que foi o objetivo do projeto, revela o conteúdo histórico e social que se reflete na língua, pois ela, materializada em textos jornalísticos, está estreitamente ligada aos acontecimentos históricos e sociais de um lugar, correspondendo perfeitamente com o que está nos PCN (1997, p.22):

Dessa perspectiva, a língua é um sistema de signos histórico e social que possibilita ao homem significar o mundo e a realidade. Assim, aprendê-la é aprender não só as palavras, mas também os seus significados culturais e, com eles, os modos pelos quais as pessoas do seu meio social entendem e interpretam a realidade e a si mesmas.

Ancorado na teoria da concepção interacionista da linguagem, o projeto objetivou esclarecer os alunos de modo significativo sobre essa dinamicidade, funcionalidade e heterogeneidade própria da natureza da língua materializada na diversidade dos gêneros, estando de acordo com o que define os PCN (1998, p.21):

Todo texto se organiza dentro de determinado gênero em função das intenções comunicativas, como parte das condições de produção dos discursos, as quais geram usos sociais que os determinam. Os gêneros são, portanto, determinados historicamente, constituindo formas relativamente estáveis de enunciados, disponíveis na cultura. São caracterizados por três elementos:

1)Conteúdo temático; 2) construção composicional; 3) estilo.

Quanto à aplicação do projeto, ele foi amparado por essa concepção de linguagem e, de um modo geral, foi desenvolvido através dos seguintes eixos metodológicos orientadores da prática: a) Leitura e interpretação; b) Produção textual contextualizada; c) Análise Linguística.

Orientados pela prática do texto na sala de aula idealizada por Geraldi (p.71), os textos jornalísticos serviram como "pretexto para discussão e, posteriormente, para a produção de novo texto", dessa vez, feita pelo aluno já devidamente orientado sobre o objetivo do gênero, suas características composicionais, estilo, etc.

Parte-se metodologicamente da leitura e interpretação aprofundada porque, como Geraldi (1990, p. 170) esclarece, a leitura funciona como auxiliar e integrante da própria escrita: "É aqui, segundo 
v. 6 (2)

$322-334$

$\mathrm{jul} / \mathrm{dez}$

2016

a perspectiva que venho defendendo, que a leitura se integra ao processo de produção". Dessa perspectiva, a leitura prévia dos gêneros é um rico arsenal para conhecimento de modos de dizer, ou ver, ou entender, ou argumentar, ou descrever a sociedade, etc. conforme a funcionalidade específica de cada gênero. Por exemplo, o horóscopo tem por função principal prever o dia do signo, enquanto que a função de uma notícia é informar a sociedade sobre acontecimentos da própria sociedade.

Assim, depois da familiaridade dos alunos com certos gêneros jornalísticos, como a notícia, a reportagem, o artigo de opinião, a crônica esportiva, os classificados, horóscopo, tirinhas, charges, etc. eles produzirão, na medida do possível, seus próprios textos jornalísticos. Evidentemente, antes disso, é imprescindível apresentar e especificar cada gênero, mostrar as funcionalidades específicas deles na sociedade, os objetivos e intencionalidades de cada um, como também a maneira composicional, estrutural, temática e de estilo, conforme nos aponta Bakhtin (2011) em relação aos gêneros que circulam socialmente.

Dessa maniera, a partir da problematização, interpretação, análise, compreensão e discussão de determinado gênero, os alunos, posteriormente, realizarão a produção contextualizada dos textos desse gênero.

Após a prática de escrita, partiu-se metodologicamente à prática de análise linguística. Esta deve ser feita não com base em um "bem certinho", como diz Geraldi, mas através dos próprios textos que foram escritos pelos alunos. "O ensino gramatical somente tem sentido para auxiliar o aluno. Por isso partirá do texto dele" (GERALDI, p.74). Dessa perspectiva, o professor prepara a análise linguística a partir de leitura dos textos, identificando questões problemáticas e equivocadas neles. Depois, seleciona e trabalha na lousa, junto com os alunos, os problemas mais frequentes que foram identificados, como questões sobre a estrutura textual (sequência lógica, coerência, coesão, paragrafação), problemas sintáticos (concordância verbal, nominal, regência), morfológicos (léxico, conjugação verbal), e fonéticos (ortografia, acentuação, divisão silábica).

Além dessas questões tradicionais do ensino da gramática, a prática de análise linguística em sala irá além, analisando questões mais abrangentes referentes ao texto: 
paráfrases, citações, discursos direto e indireto, etc.) organização e inclusão de informações; etc. (GERALDI, p.74).

A prática de análise linguística tem por objetivo final e essencial "a reescrita do texto do aluno" (GERALDI, p.74). Reescrevendo-0, o aluno irá incorporar os elementos estudados na análise linguística, e, consequentemente, também aprimorar e melhorar a sua competência linguística efetivada e concretizada sobre a sua própria produção textual a que está familiarizado.

De um modo geral, o objetivo final é possibilitar aos alunos a capacidade de compreensão ativa, responsiva e crítica (BAKHTIN, 2011) dos textos jornalísticos, como também, posteriormente, orientá-los e auxiliá-los na produção desses mesmos gêneros de textos de forma consistente.

\section{Atividades desenvolvidas}

Abaixo seguem algumas amostras de atividades desenvolvidas em um colégio no Sudoeste do Paraná, e que estão relacionadas à proposta descrita acima, a saber, o trabalho relacionado com gêneros jornalísticos. Os exemplos de atividades realizados são três: 1) compreensão e produção do gênero tirinhas com fim humorístico e lúdico; 2) compreensão e produção do gênero tirinhas com fim informativo; 3) compreensão e produção do gênero classificados.

Quanto aos gêneros tirinhas com fim lúdico e tirinha com fim informativo, as aulas seguiram a sequência de Geraldi (2012), apontada anteriormente. A partir disso, leram-se e interpretaram-se exemplos dos gêneros específicos, para só a partir daí propor atividades relacionadas a eles. Em termos de gramática, exploraram-se as onomatopeias e as interjeições, visto que são comuns nesses gêneros. No estudo deste gênero específico que envolve quadrinhos, elencou-se também o estudo dos elementos principais e indispensáveis desta modalidade de texto: discurso dialogal, tipos de balões, linhas cinéticas, metáforas visuais, personagens, etc.

Além disso, no trabalho com as tirinhas com fim informativo e humorístico, estudou-se a questão da importância da linguagem não verbal, e também foi feita a diferenciação destes de outros gêneros similares, como a caricatura, charge e cartoon. Além disso, foi tratada a diferença de uso da linguagem no gênero tirinha humorística e no gênero quadrinho de caráter informativo, pois são dois usos da linguagem com 
v. 6 (2) $322-334$ jul/dez 2016

finalidades diferentes, embora partilhem similaridades bem claras, como o desenho por exemplo.

De modo geral, as produções foram satisfatórias, e os trabalhos cumpriram com a finalidade do gênero específico. Na produção de tirinha com fim cômico, abriu-se a possibilidade de trabalhar com a intergeneracidade: transformar, com as devidas alterações, uma piada em uma tirinha.

Quanto à tirinha informativa, foi uma produção contextualizada, pois aconteceu e foi motivada pelas comemorações da semana farroupilha do colégio. A partir disso, explicou-se, numa aula expositiva, sobre a história da revolução, e então, como proposta de atividade, os alunos elaboram quadrinhos de carácter informativo a partir da aula que assistiram e das informações que absorveram. A partir daí seguiramse as adequações, a revisão, e a publicação final no jornal online do colégio.

Abaixo seguem alguns resultados dessas duas atividades.

Figura 1 - Atividade do gênero tirinha informativa

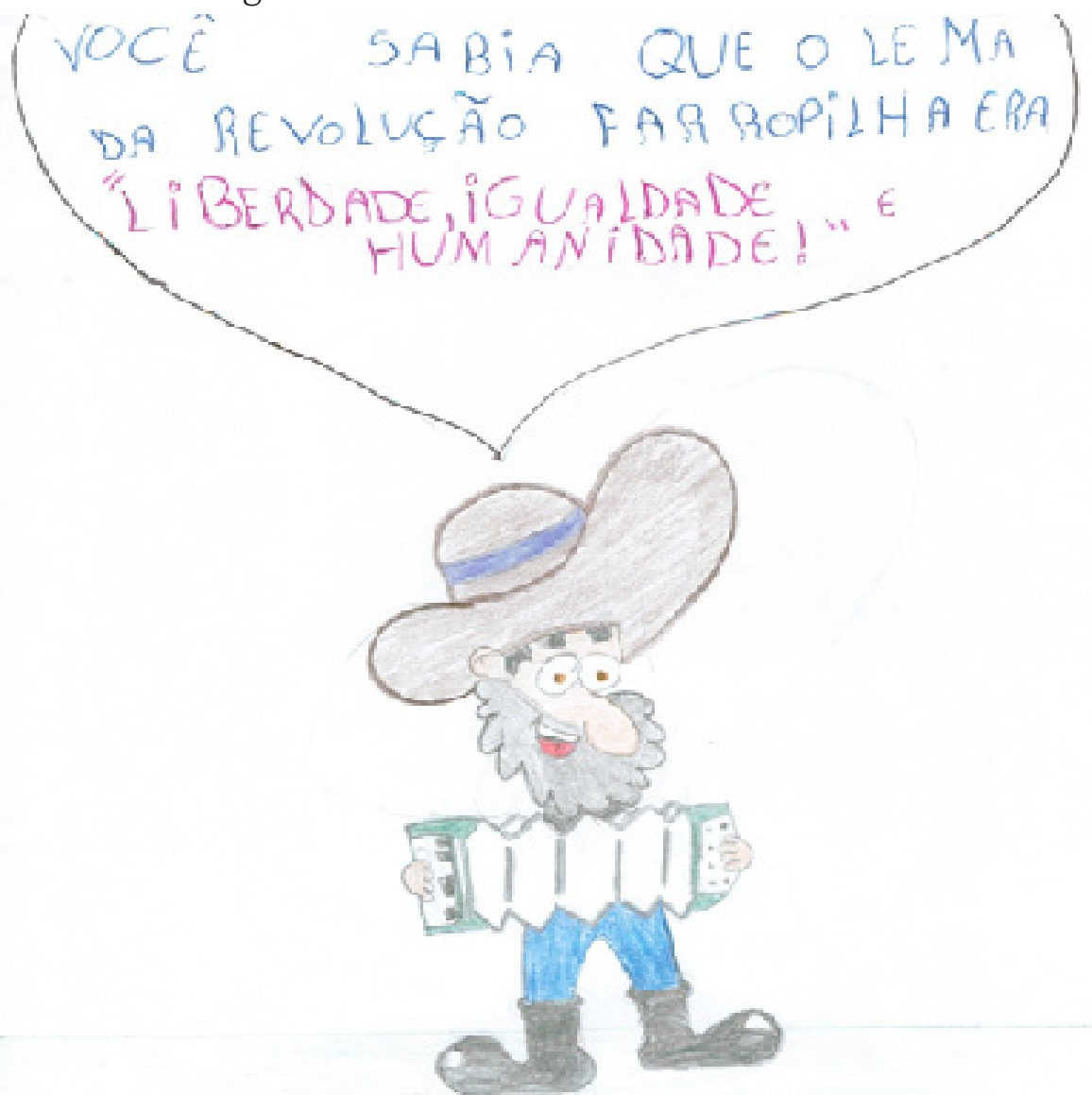


Figura 2 - Atividade do gênero tirinha informativa

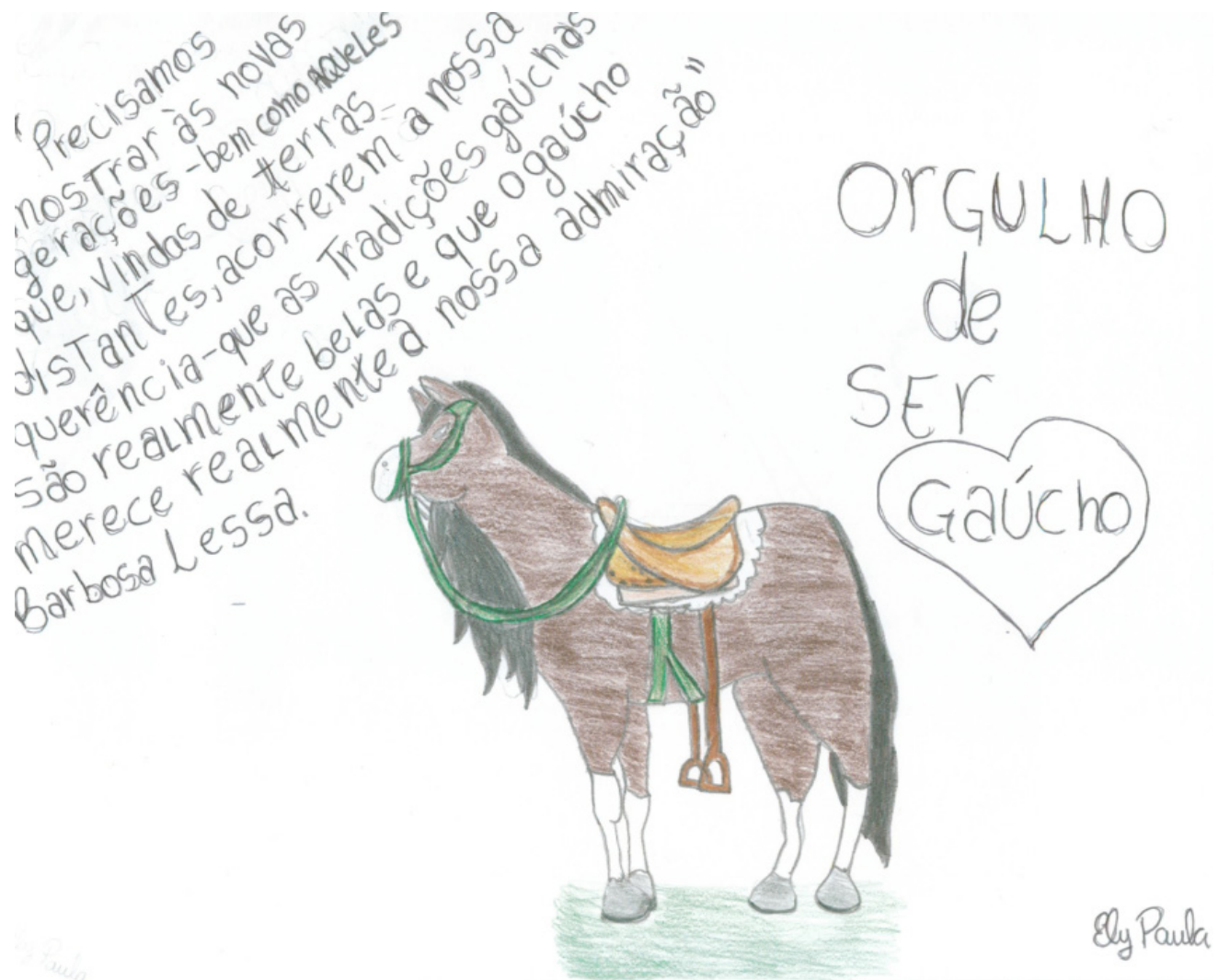

Figura 3 - Atividade do gênero tirinha humorística

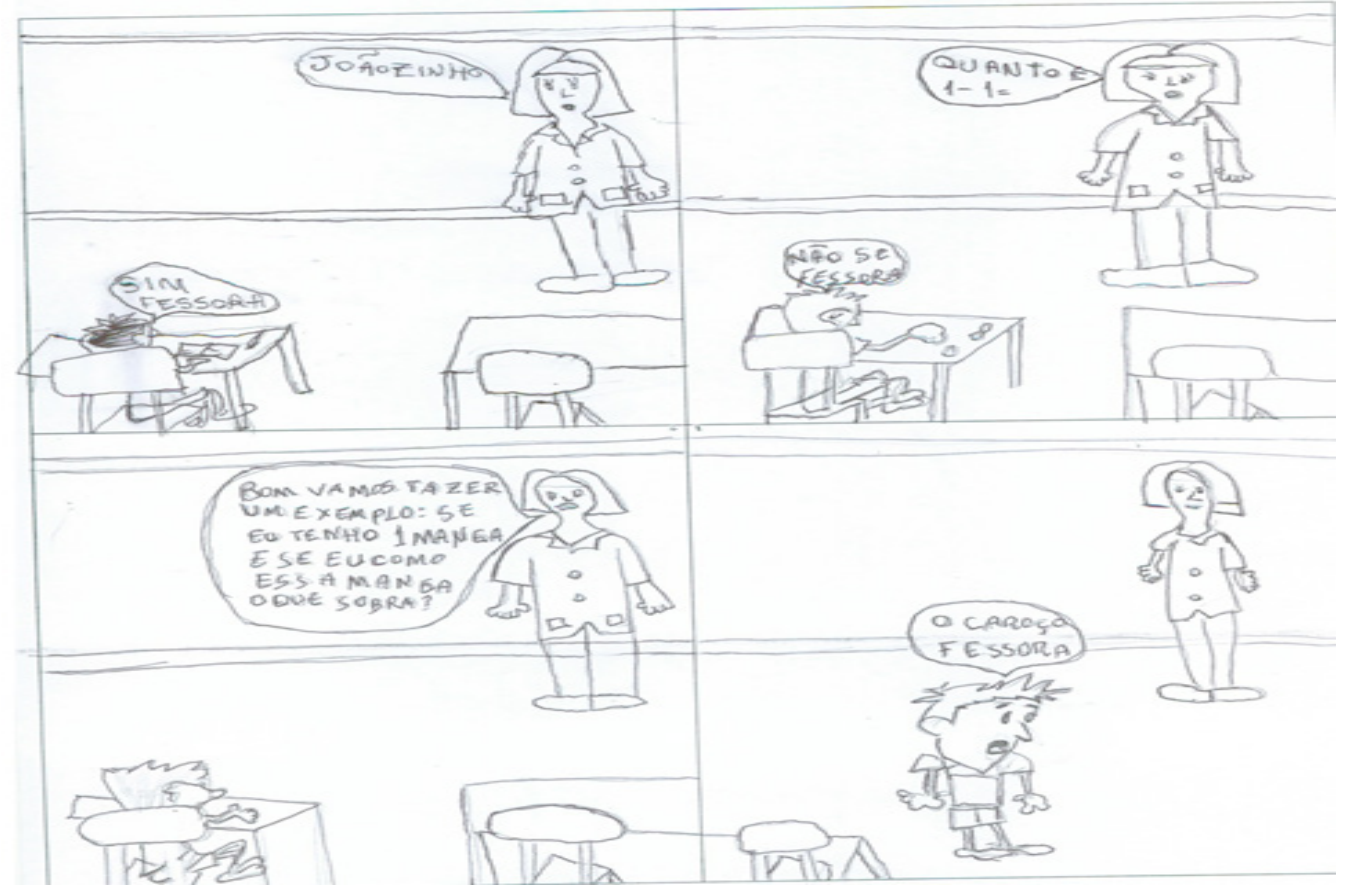


v. 6 (2) $322-334$ $\mathrm{jul} / \mathrm{dez}$ 2016

ome ana leticia.

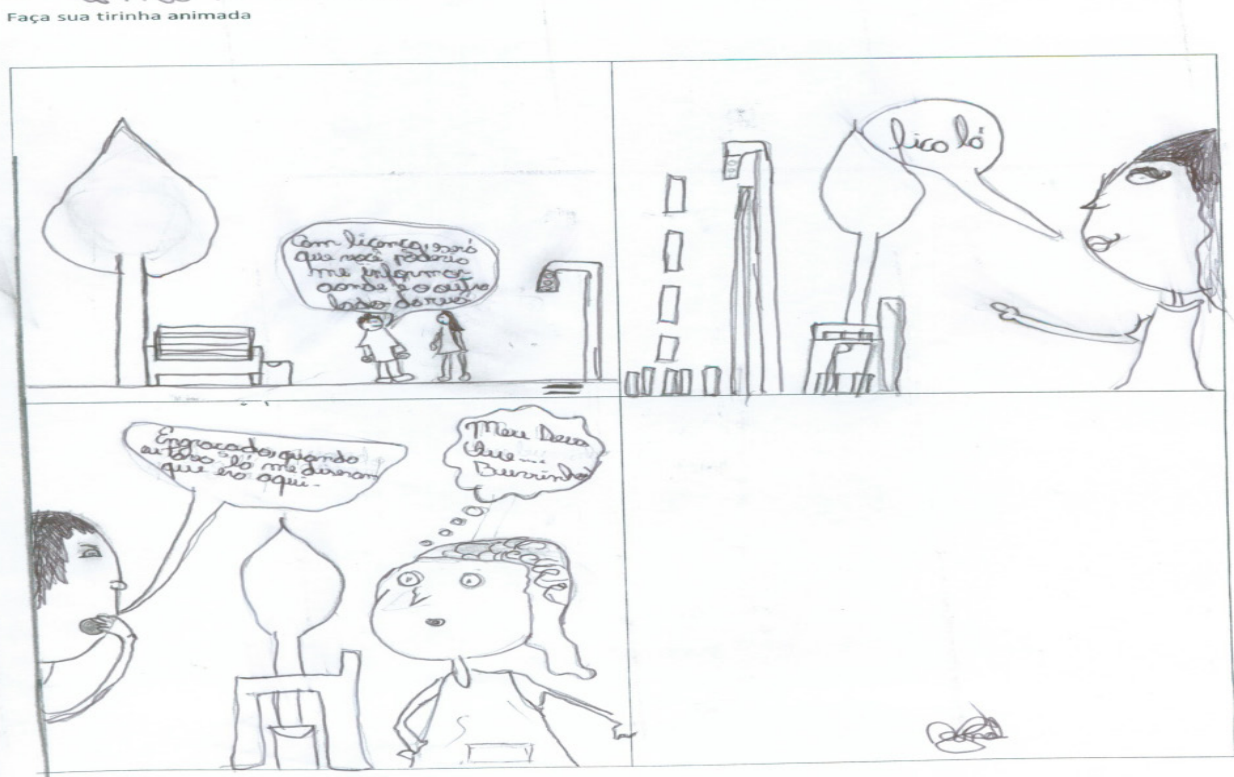

Também, como falado, trabalhou-se o gênero classificados.

O objetivo foi demostrar as principais características do gênero, esclarecendo seu fim anunciativo e propagandístico, além de apontar a estrutura composicional característica, marcado por texto curto, linguagem concisa e fragmentada do ponto de vista sintático, com palavras abreviadas que precisam ser inferidas, com uso de verbos específicos etc.

Depois da produção, analisaram-se os trabalhos e identificaramse os problemas textuais percebidos na produção, como: texto muito extenso; abreviações não realizadas; sujeito explícito (deve ser oculto) quando verbo na primeira pessoa do singular, ou indeterminado, quando verbo vem na terceira pessoa e marcado pela partícula se; falta de descritividade do objeto; verbos indevidos ou em tempo verbal inadequado (venderei); pontuação não marcada pelo uso do vírgula; palavras desnecessárias; falta de elementos essenciais, como telefone e nome do objeto.

Também, como questão relevante para confecção desse gênero, estudou-se a tipologia descritiva, que é caracterizada por descrever o que um determinado objeto tem ou possui em si. Foram exploradas a descrição de características de imóveis ou automóveis, o preço, a localização, os cômodos, área construída, etc.

Abaixo seguem alguns resultados desse gênero: 
Figura 5 - Atividade do gênero classificados

\section{CLASIFICADOS DE IMÓVEIS}

Junde-se. CASA ci $71,41 \mathrm{~m}^{2}$, contende 1 BH, 1 darm, 1 but', sel. est/gant, 1 carz

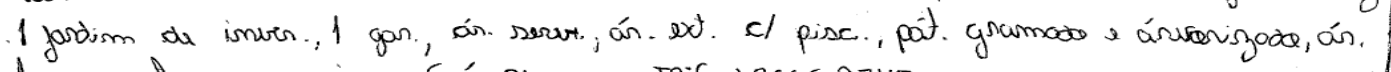
lazen á lisa sa pix., Só R\$50.000. TR:(S1) 3665.2747.

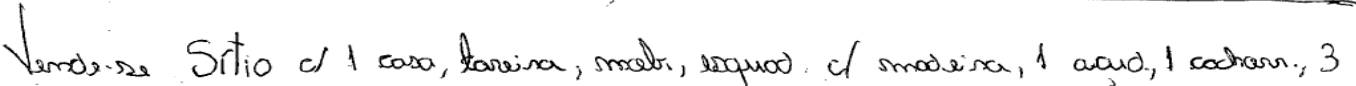

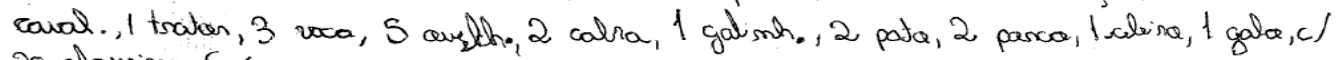
2o alqueires, SÓ 12000 SACOS DE SOJA. TR: (96) 322 '7902.

Figura 6 - Atividade do gênero classificados

\section{CLASIFICADOS DE IMÓVEIS}

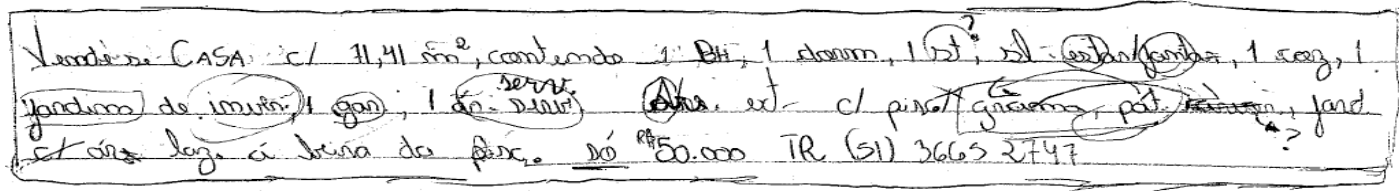

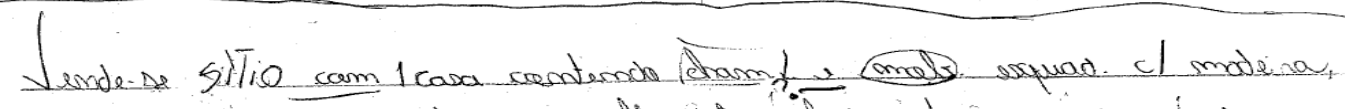

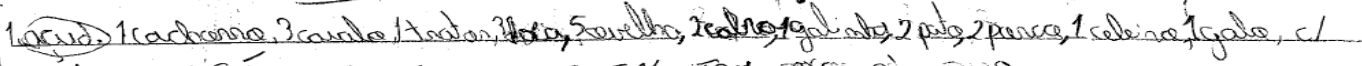

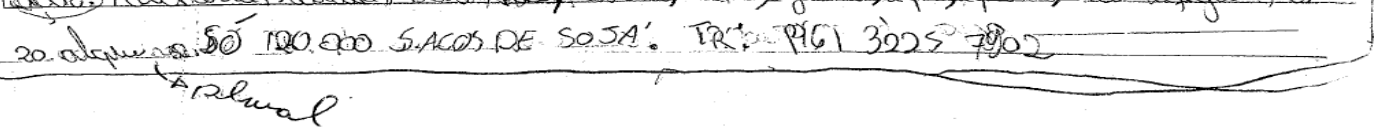

\section{Considerações finais}

O projeto teve o intuito de contribuir com a escola desenvolvendo o trabalho com um determinado uso e prática da linguagem. Assim, auxiliou a escola nesse papel essencial, que é o de "de garantir a todos os seus alunos o acesso aos saberes linguísticos necessários para o exercício da cidadania, direito inalienável de todos". (BRASIL..., 1997, p.21). O aluno precisa ter os instrumentos para, de fato, "assumir a palavra" sem medo e de uma vez por todas.

Efetivamente, as últimas teorias consideram os falantes reais e suas interações mais do que nunca. Cabe ao professor trazer os gêneros das várias esferas e camadas da sociedade, e não restringir-se apenas àqueles gêneros específicos da escola, uma vez que o seu aluno, além de estudante, é um ser social que interage com o mundo do lado de fora da sala de aula e da escola. Agindo o professor desse modo, "a língua passa 
v. 6 (2) $322-334$ jul/dez 2016

a integrar a vida através de enunciados concretos (que a realizam); é igualmente através de enunciados concretos que a vida entra na língua" (BAKHTIN, 2011, p.265).

Como resultado objetivado e alcançado, os alunos participantes tornaram-se capazes de "interpretar diferentes textos que circulam socialmente" (BRASIL, 1997, p.22) - neste caso, os textos jornalísticos - e, posteriormente, os produziram de modo individual, independentemente e contextualizado, pois a incorporação definitiva e efetiva de determinado uso de língua só se realiza através da produção de textos, que, como aponta Geraldi (1990, p. 135), é o ponto de chegada "de todo o processo de ensino/aprendizagem de língua." Portanto, eis qual é o lema: "Produzindo linguagem, aprende-se linguagem." (BRASIL, 1997, p.22).

\section{REFERÊNCIAS}

BAKHTIN, Mikhail. Estética da criação verbal. São Paulo: Editora WMF Martins Fontes, 2011.

BRASIL. Ministério da Educação, Secretaria de Educação Fundamental. Parâmetros curriculares nacionais: terceiro e quarto ciclos do ensino fundamental: língua estrangeira. Brasília, 1998.

BRASIL.Orientações curriculares para oensinoMÉDIO(OCEM). Conhecimentos de línguas estrangeiras, vol. 1, p. 85-124. Ministério da Educação, Secretaria de Educação Básica, Brasília, 2006.

BRASIL. Parâmetros curriculares nacionais: língua portuguesa. Secretaria de Educação Fundamental. Ministério da Educação, Brasília, DF, 1997.

BRASIL. Parâmetros curriculares nacionais: terceiro e quarto ciclos do ensino fundamental: língua portuguesa. Secretaria de Educação Fundamental. Brasília: DF, 1998.

GERALDI, João Wanderley. Portos de passagem. São Paulo: Martins Fontes, 1990.

Práticas de sala de aula. In: GERALDI, João Wanderley. (org.). 0 texto na sala de aula. São Paulo: Anglo, 2012, p. 57-80.

Recebido em: 09 de ago. de 2016.

Aceito em: 15 de dez. de 2016. 